\title{
Heparin-polypeptide interaction
}

\section{Near-i.r. spectroscopy in an anhydrous dispersant allows the involvement of polymer-associated water to be assessed}

\author{
David GRANT, William F. LONG* and Frank B. WILLIAMSON \\ Polysaccharide Research Group, Department of Molecular and Cell Biology, University of Aberdeen, Marischal College, \\ Aberdeen AB9 1AS, Scotland, U.K.
}

\begin{abstract}
Involvement of polymer-associated water in the interaction of heparin with poly-L-arginine and poly-L-lysine was studied by i.r. spectroscopy of complexes suspended in a non-aqueous dispersant. Movement of i.r. absorption bands due to heparin-associated water to lower frequencies upon polymer interaction indicates that hydrogen-bonding accompanies complexation. We suggest that this bonding includes water bridging between the interacting species, and that the resulting changes in water chemistry may affect the biological activity of such interacting macromolecules.
\end{abstract}

\section{INTRODUCTION}

Heparins are glycosaminoglycans composed of substituted repeating disaccharide units of $\mathrm{D}$-glucosamine and uronic acid residues. They are widely used pharmacologically as anticoagulants, are components of mast cell granules and are of uncertain physiological function. The polymers are strongly acidic polyoxyanions, $\mathrm{O}$-sulphates and $\mathrm{N}$-sulphonates being major substituents. Many possible modulations of the activities by metal ions of heparins in vivo and in vitro have been discussed (references cited in Grant et al., 1987). Not all heparin-cation interactions may be mediated by simple electrostatic binding: the possibility of the involvement of 'hydrodynamic interactions' has been suggested (Tivant et al., 1983), and a pronounced cation-dependency of the frequency and intensity in the i.r. spectrum of the absorption band arising from the water-bending mode has been reported (Grant et al., 1987). Further, a broadening of a multiplicity of bands in the i.r. fundamental region, reminiscent of spectral changes caused by strong hydrogenbonding between metal ions, water molecules and the anionic groups of polysulphonates (Zundel \& Metzger, 1968), has been noted (Grant et al., 1987). Other dependencies on cation identity of the frequency of water overtone and combination bands (Grant et al., 1987), of the strength of water binding (Grant et al., 1983, 1987) and of the degree of polymer hydration (Grant et al., 1990a) have also been observed. Hydration patterns of heparin sulphates, the components of animal cell adhesons that are structurally related to heparins, but are less $\boldsymbol{O}$-sulphated and richer in D-glucuronate residues, are different when the polymers are extracted from normal and from neoplastic cells (Grant et al., 1985), and adhesion of such cells appears to require a chemical structuring of water molecules in hydrogen-bonded arrays (Grant et al., 1988).

Dependencies on counter-cation chemistry of hydration patterns have been described for other water-miscible polyoxyanions, including polyphosphates (Glonek et al., 1972), polyacrylates (Ikegami, 1964) and inositol hexaphosphates (Costello et al., 1976). For polynucleotides, cation binding may involve water-bridging between phosphate groups and cations (Westhof, 1988), and X-ray-diffraction studies of oligosaccharide-lectin binding suggests that such bridging occurs during proteinoxyanionic saccharide interaction (Bourne et al., 1990).
In studies of polyanion-cation interactions occurring in dilute bulk aqueous solution, water molecules that are closely associated with the interacting moieties and those comprising the solvent are in fast exchange and are not readily distinguished. Examination of such interactions in the presence of a non-aqueous dispersant, in which only 'essential ' water is present, may provide insight into the mechanisms of interaction. An analogous examination of enzyme-substrate interactions in anhydrous organic solvents is providing useful information about catalytic processes (Klibanov, 1989), I.r. vibrational spectroscopy has the timeresolving power and the sensitivity to provide information about the molecular structures and interactions of molecules such as heparins (Grant et al., 1987, 1989, 1990b, 1991). In the present paper, i.r. spectroscopy of heparin-polypeptide complexes dispersed in a non-aqueous solvent is reported.

\section{EXPERIMENTAL}

The source, preparation and properties of the sodium heparin used have been previously described (Grant et al., 1987). Poly-Larginine hydrochloride (type IIB; $M_{\mathrm{r}} 60000$; batch 37C-5008), poly-L-lysine hydrochloride $\left(M_{\mathrm{r}} 40000\right.$; batch $\left.101 \mathrm{~F}-5068\right)$ and light mineral oil (nujol) were from Sigma Chemical Co., Poole, Dorset, U.K. For i.r. spectroscopy, $1 \mathrm{mg}$ of heparin, polypeptide or mixtures of the two in particular weight ratios were triturated briefly by hand using an agate mortar and pestle. After addition of $9 \mathrm{mg}$ of dried nujol, samples were triturated for a further $3 \mathrm{~min}$. Further trituration, or the addition of larger amounts of nujol, did not alter the homogeneity of the mixture, or the spectra of the dispersed material. Spectra were obtained using a Grubb Parsons Mark III grating dispersive spectrometer. For examination of samples in nujol, standard mull cells of $0.05 \mathrm{~mm}$ pathlength (Specac, Orpington, Kent, U.K.) were fitted with new, round $\mathrm{BaF}_{2}$ windows held in place with rubber gaskets. Spectra of aqueous solutions $(10 \%, \mathrm{w} / \mathrm{v})$ were obtained using a demountable solution cell fitted with new $\mathrm{BaF}_{2}$ windows, a $1 \mathrm{~mm}$ Teflon spacer and rubber gaskets. An average heparin disaccharide residue was taken to be hexadecahydrated (Atkins et al., 1974; Grant et al., 1990b) tetrasodium 2-O-sulphatoiduronosyl- $\mathrm{N}$-glucosamine 6-O-sulphate.

\footnotetext{
* To whom correspondence should be sent.
} 


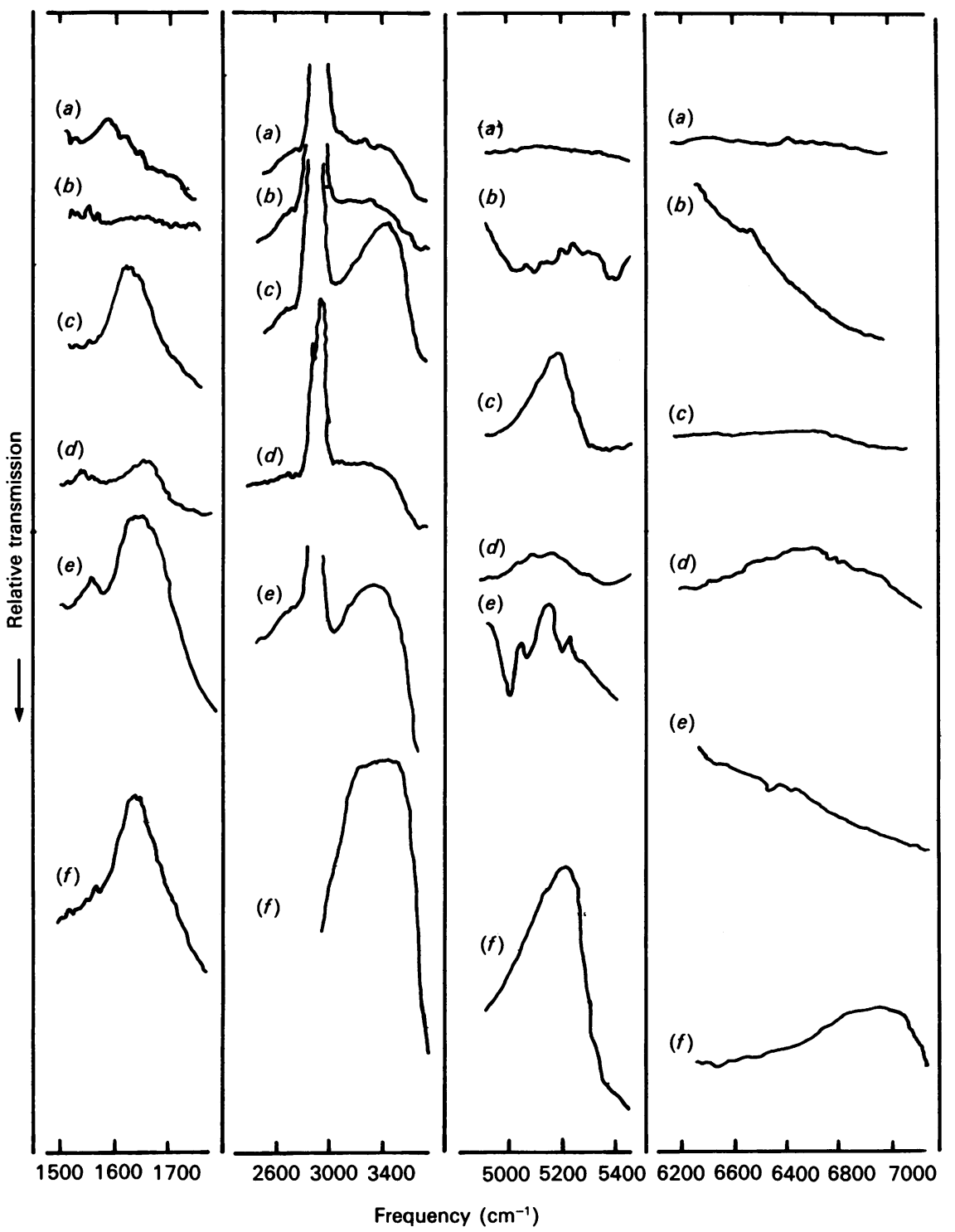

Fig. 1. I.r. Spectra of absorbances due to water

(a) Poly-L-arginine; $(b)$ poly-L-lysine; $(c)$ heparin ; $(d)$ heparin-poly-L-arginine; $(e)$ heparin-poly-L-lysine; $(f)$ heparin. Spectra $(a-e)$ were obtained using anhydrous nujol dispersant; spectrum $(f)$ was obtained in aqueous solution. Spectra $(d)$ and $(e)$ were generated using mixtures in which the (heparin disaccharide residue)/(polypeptide monomer residue) ratio was 0.3 .

\section{RESULTS AND DISCUSSION}

In addition to allowing polymer-associated water to be examined in the absence of a bulk water phase, the use of a nonaqueous dispersant has a number of practical advantages. The chemical nature and geometric shape of spectrophotometer cells containing small volumes of aqueous solutions produce surface effects which are communicated to the bulk phase and which can be detected in spectra ; in such circumstances, the use of chemically inert surfaces such as high-density polyethylene or oxidized aluminium at best minimizes these effects. Internal heating of the sample is avoided in the presence of a thermally conducting dispersant of low dielectric constant. Evaporation of thin films of aqueous solutions held between cell windows is likewise avoided, and any possible water-structuring nucleation initiated by macromolecular complexes is not propagated through the medium. Further, much biologically relevant interaction of heparins and heparan sulphates with proteins is likely to occur in pericellular and intracellular environments that are poorly represented by experiments in which the molecules are brought together in dilute aqueous media.

Fig. 1 shows portions of the spectra of sodium heparin, poly$\mathrm{L}$-arginine, poly-L-lysine, and mixtures of heparin and the two polypeptides dispersed in nujol. Fig. 1 also shows the corresponding parts of a spectrum of an aqueous solution of heparin. The polypeptides were chosen as simple models representing the more complex proteins with which heparin interacts biologically. Thus the heparin-binding site on the best explored of these, antithrombin, appears to consist of clusters of arginine and lysine residues (Sun \& Chang, 1990).

Major absorbances due to water centre around frequencies of about $1630 \mathrm{~cm}^{-1}$ (N-O-H bending), $3400 \mathrm{~cm}^{-1}$ (O-H stretching), $5200 \mathrm{~cm}^{-1}$ (a combination of bending and stretching modes) and $6900 \mathrm{~cm}^{-1}$ (first overtone of the $\mathrm{O}-\mathrm{H}$ stretching). Broad peaks seen in the spectrum of heparin in aqueous solution (Fig. $1 f$ ) are typical of absorbances due to the bulk water solvents; essentially similar patterns were observed in spectra of aqueous solutions of the two polypeptides either alone or mixed with heparin (results 


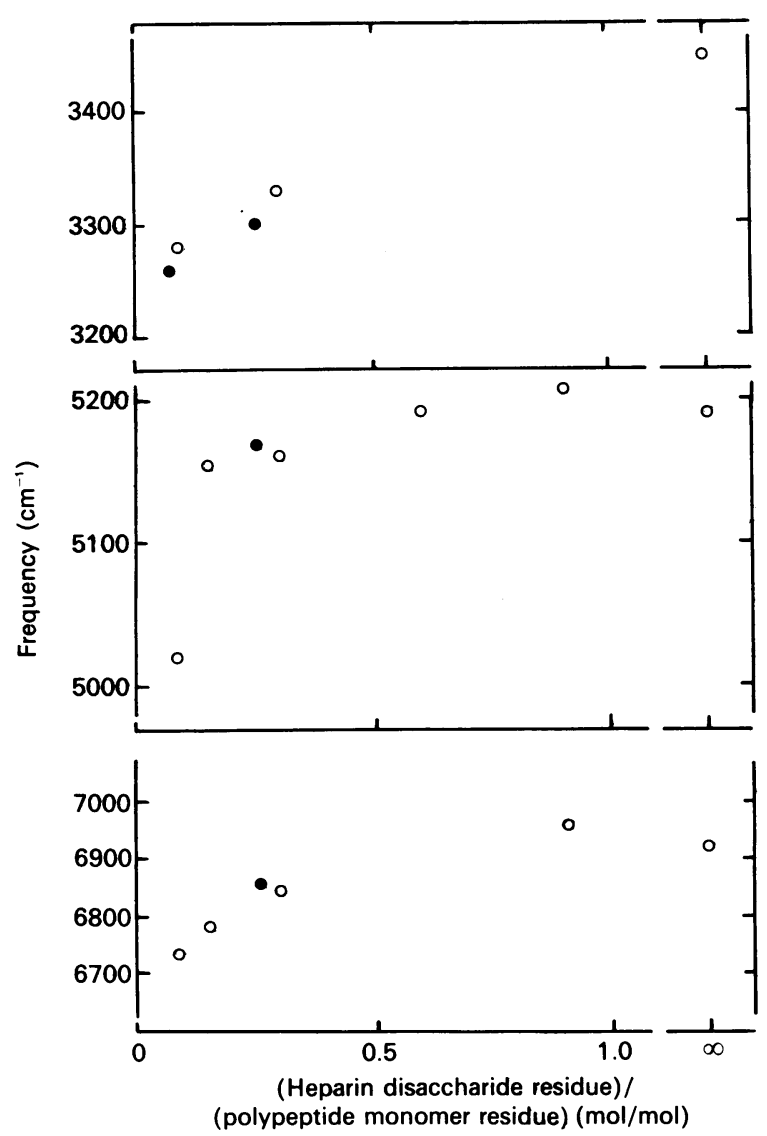

Fig. 2. Frequency of major water absorbancies as a function of the (heparin disaccharide residue)/(polypeptide monomer residue) ratio

Spectra from which the Figure was derived were obtained using anhydrous nujol dispersant. Complexes contained poly-L-arginine (O) or poly-L-lysine (O).

not shown). In contrast, the spectra obtained with nujol indicate that the addition of a cationic polypeptide to heparin causes a decrease in the vibrational frequencies of absorbancies due to heparin-associated water. Fig. 2, in which the frequencies of the major water absorbances are plotted against the heparin/ polypeptide ratio, shows that this decrease occurs over a narrow range of ratios. The $\mathrm{H}-\mathrm{O}-\mathrm{H}$ bending absorbance is not included in Fig. 2 because the amide I absorbance at about $1660 \mathrm{~cm}^{-1}$ partly obscures the water absorbance in spectra of heparin/ polypeptide mixtures (Fig. 1). However, Fig. 1 suggests that the bending absorption does move towards higher frequencies in the spectra of the heparin/polypeptide mixtures. This change accords with the idea that stronger hydrogen-bonding accompanies complexation (Everrall, 1973).

Cationic polypeptides are closely associated with chemically 'soft' water bound in an essentially organic manner at sites that include primary amino, amide imino and amido carbonyl groups. Heparins typically contain chemically 'hard' water bound in an essentially inorganic manner at sites that include $O$-sulphates, carboxylates, secondary alcoholic hydroxy groups and glycosidic ethers. The observed decrease in the vibrational frequencies of the water absorbances upon interaction of the macromolecules is a consequence of a decrease in the Hooke's Law proportionality constant, $k$, of the absorbances involved. This suggests that hydrogen-bonding accompanies the interaction. Complexation between such macromolecular species, which contain overtly chemically incompatible water shells, is therefore likely to be driven initially by long-range energetically favourable electrostatic attraction. The complex could then be stabilized by the formation of hydrogen-bonded water. Analyses of other polyoxyanion interactions (Westhof, 1988; Bourne et al., 1990) suggests that these may take the form of water bridges between the interacting macromolecules.

Some time ago it was implied that biologically significant alterations in the conformation, stability and functioning of proteins might be achieved by agents that alter the hydration pattern of these molecules (Goto \& Isemura, 1964); chiroptical studies certainly indicate that interaction with heparin causes changes in polypeptide shape (Blackwell et al., 1977; Stone, 1977). Macro- and micro-cation effectors that cause changes in the water chemistry of polyoxyanion-water cluster complexes may similarly influence the structure and behaviour of these molecules. The demonstrated changes in polymer-associated water structure upon anionic glycosaminoglycan-cationic polypeptide interaction is therefore likely to affect the biological activity of either or both of the interacting species.

We thank Janet E. T. Archbold for carrying out some of the i.r. spectroscopy.

\section{REFERENCES}

Atkins, E. D. T., Isaac, D. H., Nieduszynski, I. A., Phelps, C. F. \& Perlin, A. S. (1974) Polymer 15, 263-271

Blackwell, J., Schodt, K. P. \& Gelman, R. A. (1977) Fed. Proc. Fed. Am. Soc. Exp. Biol. 36, 98-100

Bourne, Y., Rouge, P. \& Cambillau, C. (1990) J. Biol. Chem. 265, 18161-18165

Costello, A. J. R., Glonek, T. \& Myers, T. C. (1976) Carbohydr. Res. 46, 159-171

Everrall, R. (1973) in Water: A Comprehensive Treatise (Franks, F., ed.), vol. 3, pp. 211-291, Plenum Press, New York and London

Glonek, T., van Wazer, J. R., Mudgett, M. \& Myers, T. C. (1972) Inorg. Chem. 11, 567-570

Goto, S. \& Isemura, T. (1964) Bull. Chem. Soc. Jpn. 37, 1687-1701

Grant, D., Long, W. F. \& Williamson, F. B. (1983) Biochem. Soc. Trans. 11, 96

Grant, D., Long, W. F. \& Williamson, F. B. (1985) Biochem. Soc. Trans. 13, 389

Grant, D., Long, W. F. \& Williamson, F. B. (1987) Biochem. J. 244, 143-149

Grant, D., Long, W. F. \& Williamson, F. B. (1988) Biochem. Soc. Trans. 16, 1029-1030

Grant, D., Long, W. F., Moffat, C. F. \& Williamson, F. B. (1989) Biochem. J. 261, 1035-1038

Grant, D., Long, W. F. \& Williamson, F. B. (1990a) Biochem. Soc. Trans. 18, 1293-1294

Grant, D., Long, W. F., Moffat, C. F. \& Williamson, F. B. (1990b) Biochem. Soc. Trans. 18, 1283-1284

Grant, D., Long, W. F., Moffat, C. F. \& Williamson, F. B. (1991) Biochem. J. 275, 193-197

Ikegami, A. (1964) J. Polym. Sci. (Part A) 2, 907-921

Klibanov, A. M. (1989) Trends Biochem. Sci. 14, 141-144

Stone, A. L. (1977) Fed. Proc. Fed. Am. Soc. Exp. Biol. 36, 101-106

Sun, X.-J. \& Chang, J.-Y. (1990) Biochemistry 29, 8957-8962

Tivant, P., Turq, P., Drifford, M., Magdelenat, H. \& Menez, R. (1983) Biopolymers 22, 643-662

Westhof, E. (1988) Annu. Rev. Biophys. Biophys. Chem. 17, 125-144

Zundel, G. \& Metzger, H. (1968) Z. Phys. Chem. (Neue Folge) 59, 225-241 